\title{
Major risk factors for atherosclerosis and metabolic syndrome: The UHS
}

Background: Metabolic syndrome (MetS) is associated with increased the risk of cardiovascular disease and stroke. We assessed the factors of greater association with atherosclerosis and diagnosis of MetS in the urban population of volunteers and non-athletes. The objective was to determine the risk factors for atherosclerosis and MetS in the urban adult population of Uberlândia.

Methods: A study with a sample of 101 volunteers ( $50.49 \%$ men; mean age $56.5 \pm 18$, range $19-74$ years) drawn from the Uberlândia Heart Study (UHS). The volunteers were examined in relation to physical examination and laboratory tests.

Results: The study sample was 48 women (W) and 52 man (M) years, and $48.5 \%$ were W, $40.2 \%$ was elevated blood pressure [BP (systolic BP $\geq 130 \mathrm{mmHg}$ or diastolic BP $\geq 85 \mathrm{mmHg}$ )], $39.3 \%$ of patients were obese, $61.8 \%$ had abdominal obesity, $32 \%$ of hypertriglyceridemia, $33.2 \%$ of low HDL-C and LDL-C, $40.2 \%$ of high total cholesterol, 33.2\% high non-HDL-C, $22.7 \%$ had mixed dyslipidemia, $20.2 \%$ had impaired fasting glucose and $41.1 \%$ had metabolic syndrome.

Conclusion: The UHS study reported a high prevalence of MetS and risk factors in both sexes.

Keywords: Prevalence - Risk factors - Abdominal obesity • Lipids - Metabolic syndrome

\section{Background}

Cardiovascular disease (CVD) arising from atherosclerosis is a leading cause of death and morbidity worldwide, and the underlying pathogenesis involves an imbalanced lipid metabolism and a maladaptive immune response entailing a chronic inflammation of the arterial wall1. Metabolic syndrome is defined by a constellation of interconnected physiological, biochemical, clinical, and metabolic factors that directly increases the risk of cardiovascular disease, type 2 diabetes mellitus, and all-cause mortality $[1,2]$. In particular, the visceral fat (VF) compartment may be a pathogenic fat depot. MetS is related to any comorbidities including, impaired fasting glucose, diabetes, insulin resistance, hypertension, lipids disorders, inflammation and cancer $[3,4]$. In the NHANES study onefifth of the adult population of the USA has high cardio metabolic risk, with the prevalence of MetS being estimated at 22.9\% [2-5].
A gap in the South American literature is related to what type of comorbidities related to MetS is in adults in both sexes. The aim of this study was to verify the diversity of risk factors for atherosclerosis and MetS in UHS.

\section{Materials and Methods}

\section{Study sample}

The study was approved by the institutional review boards of the Federal University of Uberlândia. All subjects provided written informed consent. A study with 101 volunteers of randomly selected adult urban population and not athlete $(50.49 \%$ men; mean age $56.5 \pm 18$, range $19-74$ years) drawn from the Uberlândia Heart Study underwent physical assessment, laboratory tests, and also did not make the use of tobacco and drugs that could influence blood pressure (BP), lipid profile and blood glucose.
Roever $\mathrm{L}^{1 *}$, Resende ES1, Diniz ALD', Penha-Silva N' ${ }^{1}$, RoerverBorges $\mathrm{AS}^{2}$, Veloso $\mathrm{FC}^{1}$, CasellaFilho $\mathrm{A}^{3}$, Dourado $\mathrm{PMM}^{3}$ and Chagas $A C P^{3,4}$

'Department of Clinical Research, Federal University of Uberlândia, Araguari, Brazil ${ }^{2}$ Heart Institute (InCor), Master Institute of Education President Antonio Carlos, IMEPAC, Araguari, Brazil ${ }^{3}$ HCFMUSP, University of São Paulo Medical School, São Paulo, Brazil ${ }^{4}$ Department of Medicine ABC, University of São Paulo Medical School, Santo André, Brazil

*Author for correspondence:

Tel: +553488039878

E-mail: leonardoroever@hotmail.com Submitted: August 18, 2017 Accepted: September 18, 2017 Published online: September 22, 2017 


\section{Risk factor and covariate assessment}

The Risk factors (RF) and covariates were measured at the first visit. BMI, defined as weight (in kilograms) divided by the square of height (in meters), was measured at each index examination. MetS was defined according to the National Cholesterol Education Program's Adult Treatment Panel III. Individuals were classified as having MetS if they had three or more of the followings from UHS Visit 1: elevated BP (systolic BP $\geq 130 \mathrm{mmHg}$ or diastolic BP $8 \geq 5 \mathrm{mmHg}$ ); elevated TG $(\geq 150 \mathrm{mg} / \mathrm{dL})$; low HDL-C (men $<40 \mathrm{mg} / \mathrm{dL}$, women $<50 \mathrm{mg} / \mathrm{dL}$ ); impaired fasting glucose $(>100 \mathrm{mg} / \mathrm{dL})$; and elevated waist circumference (WC) (men $\geq 94 \mathrm{~cm}$, women $\geq 80$ $\mathrm{cm}$ ). Diabetes was defined as a fasting plasma glucose level $\geq 126 \mathrm{mg} / \mathrm{dL}$. Impaired fasting glucose was defined as a fasting plasma glucose level of 100 to $125 \mathrm{mg} / \mathrm{dL}$ among those not treated for diabetes. Total cholesterol, HDL-C, TG and glucose were determined by enzymatic methods after overnight fasting. Certified technicians used a random-zero sphygmomanometer to measure 2 blood pressure $(\mathrm{BP})$ readings in the sitting position after 5 minutes of rest and the mean BP of the 2 measurements was recorded. Liver enzymes $\gamma$-Glutamyltransferase (GGT-normal values 9 to $36 \mathrm{U} / \mathrm{L}$ (W) and 12-64 U/L (M)], Alanine Aminotransferase (ALT-normal up to 55 $\mathrm{U} / \mathrm{L}$ ), and Aspartate Aminotransferase (AST-normal up to $34 \mathrm{U} / \mathrm{L}$ ) were determined.

\section{Statistical analysis}

The RF was normally distributed. Sex-specific age-adjusted Pearson correlation coefficients were used to assess simple correlations between RF and MetS. Multivariable linear and logistic regression was used to assess the significance of covariate-adjusted cross-sectional relations between continuous and dichotomous RF and MetS. A p-value, 0.05 was considered to indicate significance. SPSS Version 21 software (SPSS, Chicago, IL, USA) was used.

\section{Results}

The sample population was composed of 101 volunteers.

\section{Participant characteristics}

The mean age of the study sample was $48 \mathrm{~W}$ and 52 $\mathrm{M}$, and $48.5 \%$ were women. In Table 1 was reported the description of the health variables and the distribution by age groups.

\section{Prevalence of major CVD risk factors}

The overall prevalence of elevated blood pressure was $40.2 \%$ (systolic $\mathrm{BP} \geq 130 \mathrm{mmHg}$ or diastolic $\mathrm{BP} \geq 85$ $\mathrm{mmHg}$ ), 39.3\% had obese, $61.8 \%$ abdominal obesity, $32 \%$ hypertriglyceridemia, 33.2\% low HDL-C and high LDL-C, $40.2 \%$ high total cholesterol, 33.2\% high non-

\section{Table 1: Study Sample Characteristics.}

\begin{tabular}{|c|c|c|}
\hline & Men (52) & Women (49) \\
\hline $\begin{array}{l}\text { Age, y } \\
\text { BMI, kg/m² } \\
\text { Overweight (BMI > } 25 \text { and <30)\% }\end{array}$ & $\begin{array}{c}52(13) \\
25.9(4.1) 26.9\end{array}$ & 48 (6.4) 26.3 (3.4) 26.5 \\
\hline Obesity Grade 1 (BMI>30 and >35)\% & 8 & 18 \\
\hline WC, $\mathrm{cm}$ & $96.2(11.9)$ & $85.2(10.9)$ \\
\hline WC $>94 \mathrm{M}$ and W $80 \mathrm{~cm} \%$ & 56. & 69. \\
\hline Triglycerides, mg/dL & $167.6(39-638)$ & $123.8(44-490)$ \\
\hline Hypertriglyceridemia >150 mg/dL \% & 40 & 24 \\
\hline HDL cholesterol, mg/dL & $45.7(11.7)$ & $52.2(11.2)$ \\
\hline $\mathrm{HDL}<40 \mathrm{M}$ and $50 \mathrm{~W}(\mathrm{mg} / \mathrm{dL}) \%$ & 35 & 33 \\
\hline LDL cholesterol, mg/dL & $115(28.4)$ & $119.7(39.4)$ \\
\hline LDL cholesterol, mg/dL > 130\% & 35 & 33 \\
\hline Total cholesterol, mg/dL & $191.3(38.4)$ & $196.2(40.3)$ \\
\hline Total cholesterol, mg/dL>200\% & 37. & 45. \\
\hline Non-HDL-C, mg/dL & $140.6(35.7)$ & $141.9(42)$ \\
\hline Non- HDL-C, >160 M and $150 \mathrm{~W}(\mathrm{mg} / \mathrm{dL}) \%$ & 33 & 35 \\
\hline Mixed Dyslipidemia \% & 13. & 33. \\
\hline AST, U/L & $17.2(7.8)$ & $12.9(2.9)$ \\
\hline $\mathrm{ALT}, \mathrm{U} / \mathrm{L}$ & $40.3(23.3)$ & $25.2(11)$ \\
\hline Gamma-GT, U/L & $43.7(34.4)$ & $25.2(17.1)$ \\
\hline Systolic blood pressure, $\mathrm{mmHg}$ & $126.4(15.4)$ & $121.3(16.8)$ \\
\hline Diastolic blood pressure, $\mathrm{mmHg}$ & $84.8(9.5)$ & $81.5(9.7)$ \\
\hline $\mathrm{EBP}, \%$ & 48.7 & 33 \\
\hline
\end{tabular}




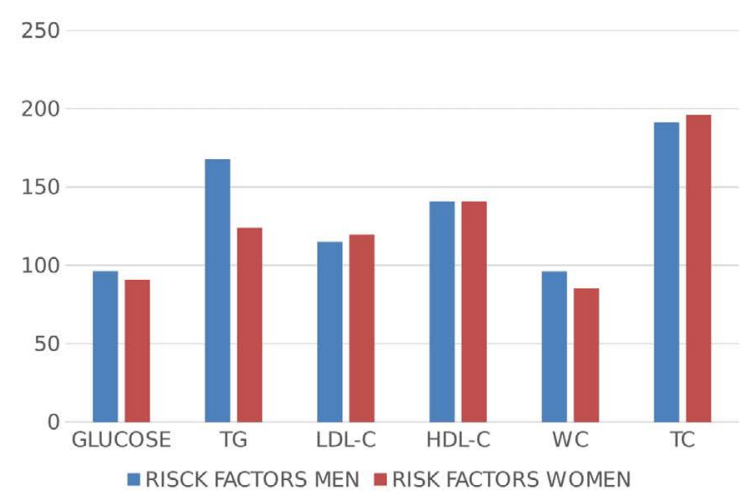

Figure 1: Prevalence (\%) of risk factors.

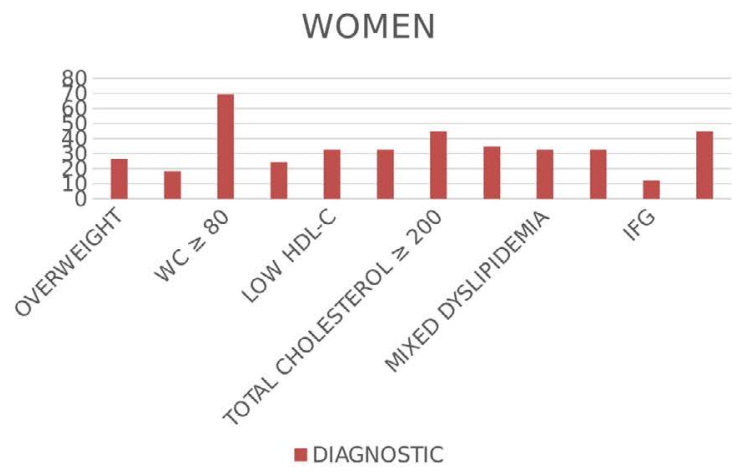

Figure 2: Prevalence (\%) in women.

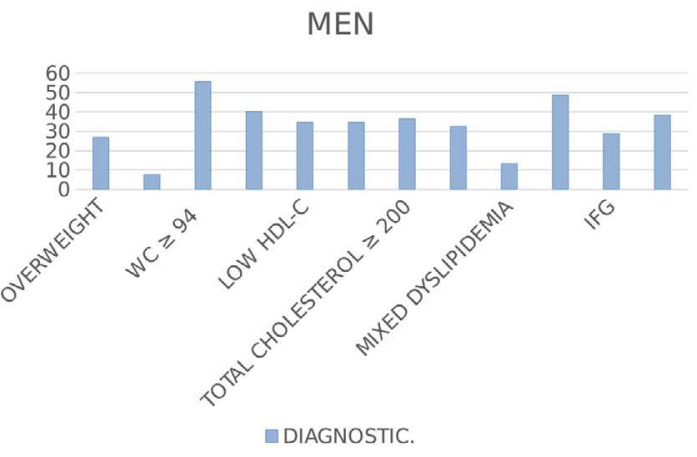

Figure 3: Prevalence (\%) in men.

HDL-C, $22.7 \%$ mixed dyslipidemia, 20.2\% impaired fasting glucose and $41.1 \%$ had MetS (Figures 1-3).

\section{Discussion}

In the UHS, $40.2 \%$ was hypertensive, $39,3 \%$ had obese, $61.8 \%$ abdominal obesity, $32 \%$ hypertriglyceridemia, $33.2 \%$ low HDL-C and high LDL-C, $40.2 \%$ high total cholesterol, $33.2 \%$ high nonHDL-C, $22.7 \%$ mixed dyslipidemia, 20.2\% impaired fasting glucose and $41.1 \%$ had MetS. The LATINMETS Brazil study reported the MetS prevalence of $4.5 \%$ in health care workers6, and The LATINMETS Columbia study identified an MS prevalence of $17.5 \%$ [6,7].
In study of latinos: obesity was rates were highest among Puerto Rican participants (for men, $40.9 \%$ and $34.7 \%$; for women); hypercholesterolemia prevalence was highest among Central American men (54.9\%) and Puerto Rican women (41.0\%). Hypertension was directly associated with CVD in both sexes as were hypercholesterolemia and obesity in women and diabetes in men). In stroke the associations were positive with hypertension in both sexes, diabetes in men, and smoking in women [7].

The (CARMELA) study verified a greater prevalence of obesity and diabetes compared with South America [8]. In INTERHEART Study, was observed one strong association of CVD with coronary syndromes $[9,10]$.

In the rural community, hypertension was present in $66.4 \%$, diabetes in $4.8 \%$, abdominal obesity in $38.46 \%$, low HDL-C, occurred in 30\%, high levels of TC in $4.5 \%$, LDL-C in $1.1 \%$, and TG in $12.5 \%$ (33). An observational study of 103 subjects (91 females and 12 males) was performed on residents of Nuevo Jerusalen, Peru. The prevalence of obesity was 30\%, elevated blood pressure was $13.3 \%$, elevated blood glucose levels was $17.9 \%$ [11-14].

Lee et al. described the prevalence of metabolic syndrome among the normal weight and overweight participants was $8.3 \%$ and $29.9 \%$ respectively. MONO prevalence was higher among males, Indians, and older participants and inversely associated with sleep duration [15]. One possible explanation may be because obesity was the most common metabolic risk factor found among participants and ectopic obesity, hyperinsulinemia, glucose intolerance, dyslipidemia and hypertension which would increase the risk of developing MetS [16]. In a study from Korea the authors relates to Met $S$ with specific gender associations and with lower socioeconomic status and psychological factors [17].

Suliga et al. evaluate the risk and frequency of occurrence of metabolic syndrome and each of its components among 3,172 individuals aged 37-66 with normal weight. MetS was diagnosed in $17.27 \%$ of individuals with normal weight. An increase in the risk of occurrence of MetS in females was observed within the second $(\mathrm{OR}=2.22)$ and the third $(\mathrm{OR}=3.97 ; 95 \%$ CI: 2.97-5.36) tertiles of normal BMI values. In males, a significantly higher risk of occurrence of MetS was noted only in the highest BMI tertile $(\mathrm{OR}=2.16)$ [18].

In a study in the rural areas of China, the authors examined 5919 hypertensive adults (2892 men and 
3027 women) aged 35 years or older. Hypertensive adults with the hypertriglyceridemic waist (HTGW) phenotype had significantly higher prevalence's of all cardiometabolic risk factors than those without the HTGW phenotype. This study concluded that the HTGW phenotype was positively associated with metabolic abnormalities in hypertensive adults [19].

Voevoda et al. relates the prevalence of METS, abdominal obesity, hypertension, hypertriglyceridemia, HDL hypocholestrolemia, LDL hypercholesterolemia, and high plasma glucose level was $17 \%$ (19.9\% in men and $14.5 \%$ in women), 42.6, 33.5, 17.5, 24.3, 64.8, and $29 \%$ respectively [20].

In Korean adolescents, approximately $50.1 \%$ and $33.1 \%$ of adolescents had at least one MetS diagnostic component according to the respective criteria [21]. Maiello et al. screened 1257 postmenopausal women. MetS was assessed on 834 women (66.4\%). Prevalence of each component was: hypertension (91.9\%), central obesity $90.9 \%)$, low HDL-C (73.3\%), high triglyceride levels (51.3\%), glucose levels higher than $110 \mathrm{mg} / \mathrm{dl}$ or diabetes (48.5\%) [22].

Huang and colleagues investigate the prevalence of MetS in 259 professional automobile drivers. The bus drivers and taxi drivers had significantly higher prevalence rates of MS than the nonoperating staff $(17.5 \% / 13.1 \%$ vs $3.3 \%)$. Professional automobile drivers have a higher prevalence rate of MS than nonoperating staff [23]. In a study in Nigerian, systemic hypertension was found in $78.45 \%$, abdominal adiposity was in $38.79 \%$ subjects and $37.93 \%$ had Type
2 diabetes mellitus [24]. In elderly Japanese-Brazilians the MetS prevalence ranged from $59.9 \%$ to $65.8 \%$ according to the different definitions. The prevalence of altered Met $S$ components was as follows: arterial blood pressure $82 \%$, fasting glycaemia $65.8 \%$, triglycerides 43.4\%, and HDL-C levels 36.9\% [25].

The MetS and risk factors for atherosclerosis may be associated with an increase in the accumulation of visceral and perirenal fat deposits in this population [26-28]. The high prevalence of MetS and risk factors for atherosclerosis may be associated with an increase in the accumulation of visceral and perirenal fat deposits in this population [26-28]. In a recent study in Ecuador, the prevalence of MetS was $66.0 \%$ in women and $47.1 \%$ in men. The MetS is high among older adults. Abdominal obesity followed by elevated blood pressure was the metabolic syndrome components more prevalent and associated with insulin resistance among older Ecuadorians [29].

\section{Strengths and Limitations}

There were obtained reliable data related to alcohol consumption and diet. Future studies should be conducted among populations of different occupations with a more representative ethnic and gender distribution at the national level, and longitudinal studies should also be conducted to establish the causal relationship between the metabolic syndrome and its risk factors.

\section{Conclusion}

The UHS study reported a high prevalence of MetS and risk factors in both sexes.

\section{Executive summary}

Background: Metabolic syndrome (MetS) is associated with increased the risk of cardiovascular disease and stroke. We assessed the factors of greater association with atherosclerosis and diagnosis of MetS in the urban population of volunteers and non-athletes. The objective was to determine the risk factors for atherosclerosis and MetS in the urban adult population of Uberlândia.

Methods: A study with a sample of 101 volunteers ( $50.49 \%$ men; mean age $56.5 \pm 18$, range 19-74 years) drawn from the Uberlândia Heart Study (UHS). The volunteers were examined in relation to physical examination and laboratory tests.

Results: The study sample was 48 women (W) and 52 man (M) years, and $48.5 \%$ were W, $40.2 \%$ was elevated blood pressure $[B P$ (systolic BP $\geq 130 \mathrm{mmHg}$ or diastolic BP $\geq 85 \mathrm{~mm} \mathrm{Hg}$ )], $39.3 \%$ of patients were obese, $61.8 \%$ had abdominal obesity, $32 \%$ of hypertriglyceridemia, $33.2 \%$ of low HDL-C and LDL-C, $40.2 \%$ of high total cholesterol, $33.2 \%$ high non-HDL-C, $22.7 \%$ had mixed dyslipidemia, $20.2 \%$ had impaired fasting glucose and $41.1 \%$ had metabolic syndrome.

Conclusion: The UHS study reported a high prevalence of MetS and risk factors in both sexes. 


\section{References}

1. Thom T, Haase N, Rosamond W, et al. American Heart Association Statistics Committee and Stroke Statistics Subcommittee. Heart disease and stroke statistics-2006 update: a report from the American Heart Association Statistics Committee and Stroke Statistics Subcommittee. Circulation. 113: e85 e151 (2006).

2. DeMarco VG, Aroor AR, Sowers JR. The pathophysiology of hypertension in patients with obesity. Nat. Rev. Endocrinol. 10(6): 364-376 (2014).

3. Daviglus ML, Talavera GA, Avilés-Santa, et al. Prevalence of Major Cardiovascular Risk Factors and Cardiovascular Diseases Among Hispanic/Latino Individuals of Diverse Backgrounds in the United States. JAMA. 308(17): 1775-1784 (2012).

4. Yusuf S, Hawken S, Ôunpuu S, et al. INTERHEART Study Investigators. Effect of potentially modifiable risk factors associated with myocardial infarction in 52 countries (the INTERHEART study): case-control study. Lancet. 364(9438): 937-952 (2004).

5. Lanas F, Avezum A, Bautista LE, et al. INTERHEART Investigators in Latin America. Risk factors for acute myocardial infarction in Latin America: the INTERHEART Latin American study. Circulation. 115(9): 1067-1074 (2007).

6. Azuma K, Katsukawa F, Oguchi S, et al. Correlation between serum resistin level and adiposity in obese individuals. Obes. Res. 11: 997-1001 (2003).

7. Vidigal FC, Ribeiro AC, Babio N, Salas-Salvadó j, Bressan j. Prevalence of metabolic syndrome and pre-metabolic syndrome in health professionals: LATINMETS Brazil study. Diabetol. Metabol. Synd. 7: 6 (2015).

8. Salaroli LB, Barbosa GC, Mill JG, et al. Metabolic syndrome prevalence in population-based study, Vitoria, ES-Brazil. Arq. Bras. Endocrinol. Metabol. 51(7): 1143-1152 (2007).

9. Schargrodsky H, Hernández-Hernández R, Champagne BM, et al. CARMELA Study Investigators. CARMELA: assessment of cardiovascular risk in seven Latin American cities. Am. J. Med. 121(1): 58-65 (2008).

10. Yusuf S, Hawken S, Ônpuu S, et al. INTERHEART Study Investigators. Effect of potentially modifiable risk factors associated with myocardial infarction in 52 countries (the INTERHEART study): case-control study. Lancet. 364(9438): 937-952 (2004).

11. Lanas F, Avezum A, Bautista LE, et al. INTERHEART Investigators in Latin America. Risk factors for acute myocardial infarction in Latin America: the INTERHEART Latin American study. Circulation. 115(9): 1067-1074 (2007).

12. Mooteri SN, Petersen F, Dagubati R, et al. Duration of residence in the United States as a new risk factor for coronary artery disease (The Konkani Heart Study). Am. J. Cardiol. 93(3): 359361 (2004).

13. Ogunmola JO, Olaifa AO, Oladapo OO, et al. Prevalence of cardiovascular risk factors among adults without obvious cardiovascular disease in a rural community in Ekiti State, Southwest Nigeria. BMC Cardiovascul. Disord. 13: 89 (2013).
14. Raju, SS, Kumar V. Prevalence of Risk Factors for Cardiovascular Disease and Type II Diabetes in Females within the Slum Nuevo Jerusalen, Peru. Int. J. Diabetes. Clin. Res. 2: 2 (2015).

15. Lee SC, Hairi NN, Moy FM. Metabolic syndrome among nonobese adults in the teaching profession in Melaka, Malaysia. $J$. Epidemiol. 27(3): 130-134 (2017).

16. Mohamud WN, Ismail AA, Sharifuddin A. Prevalence of metabolic syndrome and its risk factors in adult Malaysians: results of a nationwide survey. Diabetes. Res. Clin. Pract. 91: 239-245 (2011).

17. Cho KI, Kim BH, Je HG, et al. Gender-Specific Associations between Socioeconomic Status and Psychological Factors and Metabolic Syndrome in the Korean Population: Findings from the 2013 Korean National Health and Nutrition Examination Survey. Biomed. Res. Int. 2016: 3973197 (2016).

18. Suliga E, Kozieł D, Głuszek S. Prevalence of metabolic syndrome in normal weight individuals. Ann. Agric. Environ. Med. 23(4): 631-635 (2016).

19. Shuang C, Xiaofan G, Shasha Y, et al. Hypertriglyceridemic waist phenotype and metabolic abnormalities in hypertensive adults: A STROBE compliant study. Medicine. 95(49): e5613 (2016).

20. Voevoda MI, Koval'kova NA, Ragino YI, et al. Prevalence of metabolic syndrome in 25-45-year-old Novosibirsk dwellers. Ter. Arkh. 88(10): 51-56 (2016).

21. Kim S, So WY. Prevalence of Metabolic Syndrome among Korean Adolescents According to the National Cholesterol Education Program, Adult Treatment Panel III and International Diabetes Federation. Nutrients. 1: 8(10) (2016).

22. Maiello M, Zito A, Ciccone MM, et al. Metabolic syndrome and its components in postmenopausal women living in southern Italy, Apulia region. Diabetes. Metab. Syndr. 11(1): 43-46 (2017).

23. Huang HY, Wang W, Zhou JP, et al. Metabolic syndrome and its influencing factors in professional automobile drivers in a company. Diabetes. Metab. Syndr. 34(4): 258-261 (2016).

24. Nalado AM, Musa BM, Gezawa ID, et al. Prevalence of metabolic syndrome among apparently healthy adults in a rural community, in north-western Nigeria. Niger. J. Med. 24(4): 323330 (2015).

25. Xavier NP, Chaim RC, Gimeno SGA, et al. Prevalence of metabolic syndrome in elderly Japanese-Brazilians. Med. Sci. Monit. 18: PH1-PH5 (2012).

26. Roever L, Resende ES, Veloso FC, et al. Abdominal Obesity and Association with Atherosclerosis Risk Factors. Medicine. 95: e1357 (2016).

27. Roever L, Resende ES, Veloso FC, et al. Ectopic adiposopathy and association with cardiovascular disease risk factors: The Uberlândia Heart Study. Inter. J. Cardiol. 190: 140-142 (2015).

28. Roever L, Resende ES, Veloso FC, et al. Perirenal Fat and Association with Metabolic Risk Factors. Medicine. 94: e1105 (2015).

29. Orces $\mathrm{CH}$, Gavilanez EL. The prevalence of metabolic syndrome among older adults in Ecuador: Results of the SABE survey. Medicine. 4021(17): 30073-30075 (2017). 